\title{
Chronic anthropogenic noise disrupts glucocorticoid signaling and has multiple effects on fitness in an avian community
}

\author{
Nathan J. Kleist ${ }^{a, b, 1}$, Robert P. Guralnick ${ }^{c}$, Alexander Cruz ${ }^{a}$, Christopher A. Lowry ${ }^{d, e}$, and Clinton D. Francis ${ }^{f}$ \\ aDepartment of Ecology and Evolutionary Biology, University of Colorado Boulder, Boulder, CO 80309; ${ }^{\circ}$ Department of Environmental Science and Ecology, \\ The College at Brockport, State University of New York, Brockport, NY 14420; 'University of Florida Museum of Natural History, University of Florida,

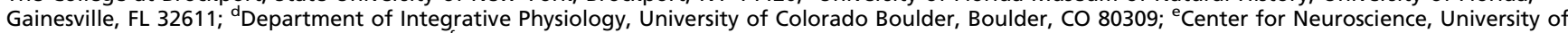 \\ Colorado Boulder, Boulder, CO 80309; and 'Department of Biological Sciences, California Polytechnic State University, San Luis Obispo, CA 93407
}

Edited by Bruce S. McEwen, The Rockefeller University, New York, NY, and approved November 14, 2017 (received for review June 2, 2017)

\begin{abstract}
Anthropogenic noise is a pervasive pollutant that decreases environmental quality by disrupting a suite of behaviors vital to perception and communication. However, even within populations of noise-sensitive species, individuals still select breeding sites located within areas exposed to high noise levels, with largely unknown physiological and fitness consequences. We use a study system in the natural gas fields of northern New Mexico to test the prediction that exposure to noise causes glucocorticoidsignaling dysfunction and decreases fitness in a community of secondary cavity-nesting birds. In accordance with these predictions, and across all species, we find strong support for noise exposure decreasing baseline corticosterone in adults and nestlings and, conversely, increasing acute stressor-induced corticosterone in nestlings. We also document fitness consequences with increased noise in the form of reduced hatching success in the western bluebird (Sialia mexicana), the species most likely to nest in noisiest environments. Nestlings of all three species exhibited accelerated growth of both feathers and body size at intermediate noise amplitudes compared with lower or higher amplitudes. Our results are consistent with recent experimental laboratory studies and show that noise functions as a chronic, inescapable stressor. Anthropogenic noise likely impairs environmental risk perception by species relying on acoustic cues and ultimately leads to impacts on fitness. Our work, when taken together with recent efforts to document noise across the landscape, implies potential widespread, noise-induced chronic stress coupled with reduced fitness for many species reliant on acoustic cues.
\end{abstract}

acoustic environment | anthropogenic noise | birds | stress response | perceived predation risk

$\mathbf{H}$ uman-made noise is a widespread and complex stimulus that alters habitats, degrades natural acoustic conditions, and partially or fully excludes species that are sensitive to noise exposure from affected areas (1-4). The exact mechanisms by which noise disrupts animals and their environments are still debated, but recent work links noise exposure with alterations in vocalization, vigilance, foraging, and parental behavior (5-12). Despite this recent progress, key questions remain unanswered, especially whether anthropogenic noise represents a chronic stressor for free-living animals and the severity of any resulting fitness effects from noise or noise-induced stress. Although not unexplored (1320), the effect of noise on stress and fitness is complex (21). The identification of mechanisms is especially difficult given the possibility that noise could elicit a stress response directly through extreme exposure $(22,23)$ or indirectly by altering the interaction between animals and their environment (13). Noise levels in wild systems reach the extreme amplitudes that are observed to directly elicit stress responses in laboratory studies [i.e., 90-105 dB (23); $130 \mathrm{~dB}(24)]$ only at very close proximity to noise sources. At lower exposure levels, anthropogenic noise is more likely to elicit stress responses indirectly by increasing the difficulty of coping with external challenges (e.g., territory defense) or by creating anxiety through reduced detectability and predictability of threats (e.g., acoustic masking of predator alarm sounds) (8, 24-26), or both. Clarifying the potential impacts of chronic noise exposure in wildlife is timely and needed, given the nearly ubiquitous presence of anthropogenic noise worldwide and the forecasted global rise in noise-producing infrastructure (1).

Conservation physiologists often use measurements of an organism's baseline circulating stress hormones, or glucocorticoids (GCs), as an indirect measure of habitat quality and a proxy measure for potential fitness (27). GCs are secreted from the adrenal gland in a coping response to challenge and are the result of activation of the hypothalamic-pituitary-adrenal (HPA) axis, a chemical cascade triggered by neuronal signals sent from hierarchical neural systems to the hypothalamus in response to the brain's perception of a stressor $(28,29)$. The HPA axis is a highly conserved vertebrate stress system activated during allostasis, the process by which animals maintain stability, or homeostasis, through change (30). While GCs are modulated in ultradian, circadian, and seasonal rhythms to meet challenges related to predictable energy deficits, frequent disturbance from chronic stressors encountered in low-quality habitats can push an

\section{Significance \\ Studies examining relationships among habitat disturbance, physiology, and fitness in wild animals often produce contra- dictory or inconclusive results, casting doubt on current con- servation physiology predictive frameworks linking stress and fitness. We apply a new framework drawn from experimental systems utilizing chronic inescapable stressors to explore how noise, an environmental stimulus common to wildlife habitats worldwide, disrupts stress hormone signaling and impacts fit- ness. We utilize a natural experiment to show that chronic, an- thropogenic noise reduced baseline corticosterone levels, increased acute corticosterone response, and, at highest amplitudes, nega- tively impacted multiple measures of fitness across three species of birds. Our work brings conservation physiology theory involving wild animals into needed alignment with recent theories based on chronic stress in laboratory studies.}

Author contributions: N.J.K., A.C., and C.D.F. designed research; N.J.K. and C.D.F. per formed research; N.J.K., R.P.G., and C.D.F. analyzed data; and N.J.K., R.P.G., A.C., C.A.L., and C.D.F. wrote the paper.

The authors declare no conflict of interest.

This article is a PNAS Direct Submission.

Published under the PNAS license.

Data deposition: All data and the R code used to produce this work are available online in a Dryad digital data repository (doi:10.5061/dryad.bt45d).

${ }^{1}$ To whom correspondence should be addressed. Email: nathan.kleist@colorado.edu

This article contains supporting information online at www.pnas.org/lookup/suppl/doi:10 1073/pnas.1709200115/-/DCSupplemental. 
organism's physiological state out of the range of a normal allostasis and into a state of allostatic overload. Overload states are often pathological and have been shown to have fitness consequences $(30,31)$. Although increased allostatic load may suggest higher baseline GCs, the empirical data have been equivocal at best; different studies find decreased as well as increased GCs in response to chronic stressors $(17,25,32-36)$.

Baseline corticosterone (hereafter, "cort") levels are generally predicted to positively associate with the intensity of habitat disturbance in what has been dubbed the "cort-fitness hypothesis" $(21,27)$. In contrast to the predictions of this hypothesis, results from laboratory and human systems suggest that exposure to chronic stressors is often associated with decreased basal GC levels, hypocorticism, and GC insensitivity $(37,38)$. The development of hypocorticism could be a coping mechanism that saves an organism from experiencing the severe effects of allostatic overload (39), but there is evidence that it can lead to reduced fitness. For example, a laboratory-based system using mice shows how chronic subordinate social rank triggers hypocorticism, reflected by reduced basal GC levels and GC insensitivity that can be accompanied by an inflammatory response $(25,40)$ and reduced weight gain (41). Unlike situations in which animals fail to react to repeated chronic stressors, physiological results in this laboratory system are paired with negative fitness outcomes, suggesting that animals do not habituate (42). Additionally, these studies show that individuals experiencing hypocorticism can develop HPA-axis sensitivity to heterotypic stressors, leading to increased GC responsiveness following experimental acute stress events $(25,43)$. In natural systems, such heterotypic stressors could include predation attempts, competitor interactions, or confrontations with humans and other anthropogenic disturbances. While much work has focused on human and rodent laboratory models, the sensory blanketing of the acoustic environment by chronic anthropogenic noise provides a unique opportunity to test if a chronic, inescapable stressor can cause similar stress and fitness responses in wild animals.

The impact of noise is thought to be most severe when frequencies overlap auditory environmental cues, a phenomenon known as "acoustic masking," which leads to reduced detection and discrimination of key acoustic signals and cues. Acoustic signals and cues from both conspecifics and heterospecifics provide important information about the immediate environment, including the quality and location of competitors (44) and the presence or absence of predators through alarm or nonalarm vocalizations and adventitious sounds (45-49). Given the capacity for chronic noise to consistently mask biologically relevant cues (8, $26,47,50)$, animals living in areas with high levels of noise may fail to receive information about their local habitats, leading to a continual state of perceived unpredictability and reduced security $(44,47,51)$. The experience of constant environmental uncertainty among both parents and nestlings, whether justified or not (24), could cause chronic activation of the HPA axis and affect both GCs and fitness through reduced hatching success of eggs and provisioning of young (52).

To date, no studies have simultaneously examined relationships among noise, GCs, and fitness in animals that settle and breed in natural areas exposed to chronic anthropogenic noise. To address this significant gap and provide a needed conceptual alignment of recent work in conservation physiology with related work on chronic stress, we performed a natural experiment using wildlands in northern New Mexico's San Juan Basin, where a community of birds breeds along a gradient of noise produced by natural resources extraction (Fig. 1). We measured noise levels, cort, and fitness-relevant variables, e.g., hatching success and nestling body condition, in populations of three species of cavity-nesting birds with different tolerances to noise: western and mountain bluebirds (Sialia mexicana and Sialia currucoides, respectively), and ash-throated flycatchers (Myiarchus cinerascens) (53). We predict that long-term exposure to continuous anthropogenic noise will act as a chronic stressor, disrupting GC signaling in adults and nestlings, with the greatest impact at sites with highest amplitude noise. We also predict that long-term exposure to continuous anthropogenic noise will be linked to reduced fitness. Incorporating multiple species and disturbance (53-57) into a multiyear study defined by a chronic, homotypic stressor represents the most highly integrated study of the effects of anthropogenic noise on wild birds to date.

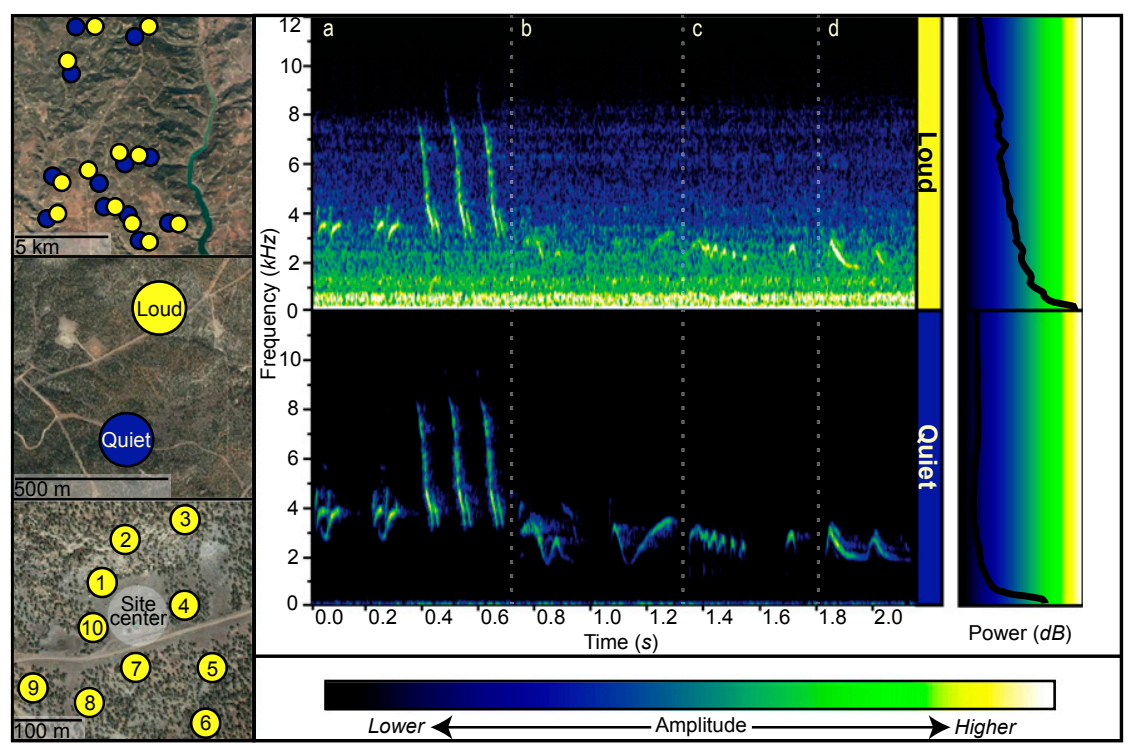

Fig. 1. This conceptual figure shows the study system design and the acoustic properties of sites with and without compressor noise. (Left) The three nested spatial scales included in the study: the full system (Top), loud and quiet pairs (Middle), and individual sites (Bottom). The Bottom shows nest boxes (labeled 1-10) arrayed around the site center, which was the centroid location of a well pad. (Center) A spectrogram of recorded background noise at a louder area (Upper) and quieter area (Lower). The songs of four common species that are found in RCHMA, including representatives from this study are included to depict the masking potential of noise: (a) spotted towhee; (b) plumbeous vireo; $(c)$ ash-throated flycatcher; and ( $d$ ) western bluebird). (Right) Power spectra that show the amplitude or "power" of compressor noise at frequencies between 0 and $12 \mathrm{kHz}$. 


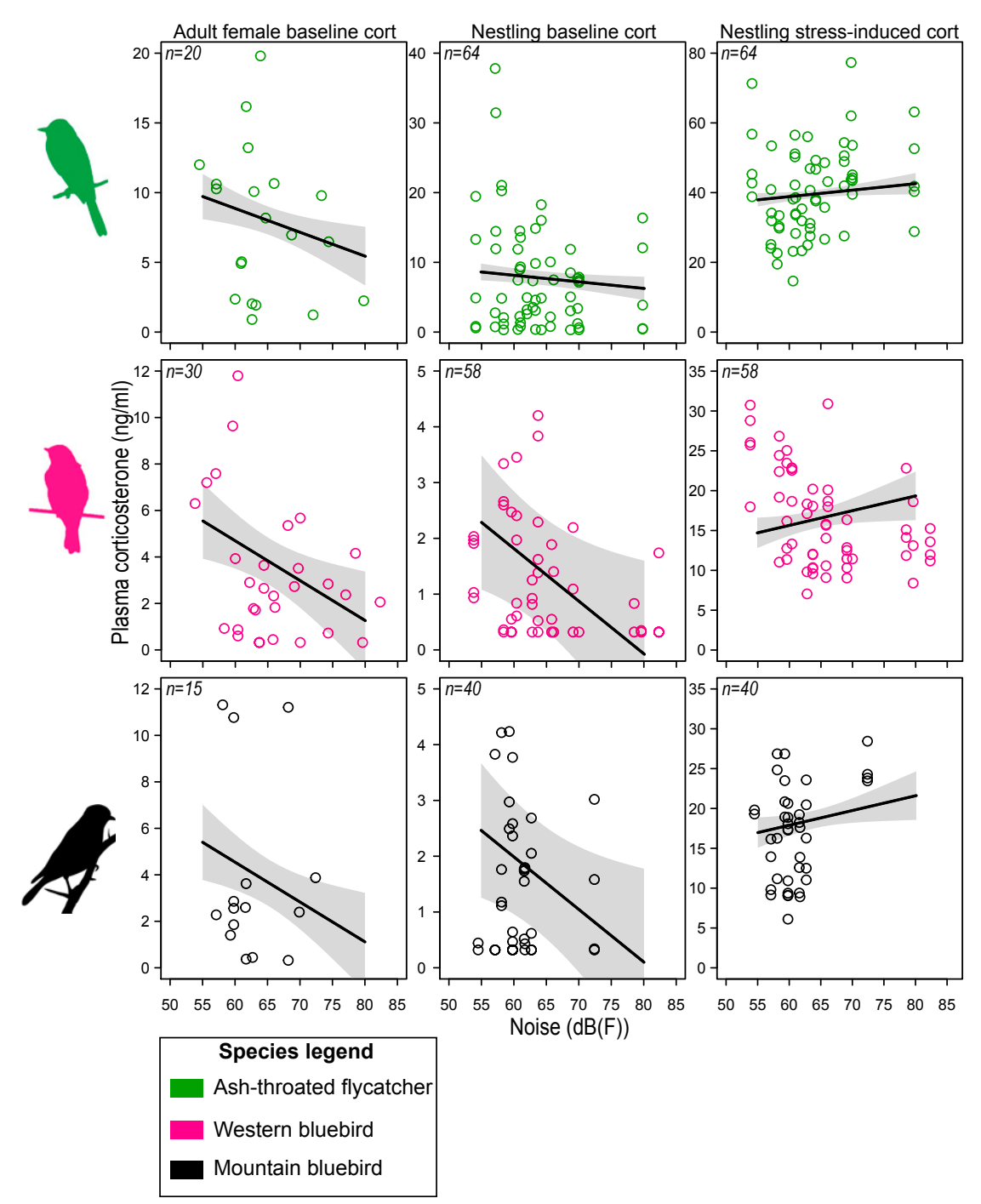

Fig. 2. The graph shows the relationship between cort and noise in all three species and two life stages. Baseline cort levels for both adults and nestlings were negatively affected by noise (Left and Center Columns, respectively), while acute stress-induced cort levels in nestlings were positively affected by noise (Right Column). For each model, the effect of noise was consistent across species, irrespective of species-specific cort levels. The gray-shaded areas indicate the $85 \% \mathrm{Cls}$ for each estimated effect.

\section{Results and Discussion}

Effect of Noise on Cort. The amplitude of compressor noise, measured as equivalent continuous sound level $\left(\mathrm{L}_{e q}, \mathrm{~dB}\right.$ unweighted $[\mathrm{dB}(\mathrm{F})])$, had a negative effect on baseline cort levels in adult females [linear mixed model (LMM), Gaussian distribution, $\beta_{\text {noise }}=-1.120,85 \%$ CI: -1.966 to -0.279 ] (Fig. 2 and Table 1 ). This result, which was consistent across species, supports our prediction that chronic anthropogenic noise exposure is an explanatory factor affecting GC signaling. The finding of a negative linear relationship between noise disturbance and baseline cort strongly suggests that suppression of baseline cort occurs in response to the acoustic disturbance gradient. While it remains possible that individual GC responsiveness affects nest site selection, we do not find any evidence of self-sorting based on other quality factors, e.g., body size (Table S1). This relationship is best explained by the development of hypocorticism, a physiological condition consistent with exposure to chronic stress $(25,39,40)$. A previous study found that an experimental chronic stress protocol reduced baseline cort levels among wildbreeding female European starlings (Sturnus vulgaris) relative to individuals in a control group (32).
Nestlings in our study also showed reduced levels of baseline cort with increased noise levels, and, as in adults, there was support for a common effect across species (LMM, Gaussian distribution, $\beta_{\text {noise }}=-0.660,85 \%$ CI: -1.243 to -0.080 ) (Fig. 2 and Table 1). A comparable result was found in a small-scale experimental study that reported reduced baseline cort in white-crowned sparrow (Zonotrichia leucophrys) chicks exposed to noise during their first $5 \mathrm{~d}$ of life (17). That we find a clear negative effect on cort across a gradient of noise in females and nestlings from three different species strongly suggests that chronic anthropogenic noise induces stress and hypocorticism in birds.

Research from the field of sensory ecology demonstrates how masking of critical acoustic communications by chronic noise could lead to stress. The distance over which birdsong and other sounds are effectively transmitted, their "active space" (58), is significantly reduced by increases in ambient background noise (1, 8, 59-61). Anthropogenic noise, acting as an acoustic blanket, can reduce or inhibit detection of hetero- $(46-48)$ and conspecific (62) vocalizations that birds and other animals (45) use to gain information about predation threats. For example, the presence of birdsong and chatter is thought to signal the absence of nearby predators $(49,63)$. Thus, 
Table 1. Effects of noise and other variables on cort and fitness

\begin{tabular}{|c|c|c|c|c|c|c|c|c|}
\hline Dependent variable & $N$ & Fixed effects & Random effects & $\mathrm{k}$ & $\mathrm{R}^{2}$ & $\mathrm{AIC}_{\mathrm{c}}$ & Null $\mathrm{AIC}_{\mathrm{c}}$ & $\chi^{2}$ \\
\hline \multicolumn{9}{|l|}{ Cort predicted by noise } \\
\hline Adult baseline cort & 65 & $\begin{array}{c}\text { Noise*_- }^{*} \\
\text { Species* } \\
\text { Life stage* }\end{array}$ & $\begin{array}{c}\text { Site } \\
\text { Nest ID }\end{array}$ & 8 & 0.592 & 369.801 & 381.857 & $<0.001$ \\
\hline Nestling baseline cort & 162 & $\begin{array}{l}\text { Noise*_- } \\
\text { Species* }\end{array}$ & Year & 6 & 0.319 & 978.299 & $1,030.426$ & $<0.001$ \\
\hline Nestling acute stressor-induced cort & 161 & $\begin{array}{c}\text { Noise*}^{*}+ \\
\text { Species* } \\
\text { Chicks*+ } \\
\text { Time*_- } \\
\text { Tree cover*+ }\end{array}$ & Nest ID & 9 & 0.766 & $1,134.000$ & $1,202.198$ & $<0.001$ \\
\hline \multicolumn{9}{|l|}{ Fitness predicted by noise } \\
\hline All species hatch success & 364 & Intercept & None & 1 & 0 & 218.722 & $\mathrm{Na}$ & $\mathrm{Na}$ \\
\hline Western bluebird hatch success & 133 & $\begin{array}{c}\text { Noise }^{*}- \\
\text { Tree cover* }\end{array}$ & None & 3 & 0.039 & 89.489 & 91.538 & 0.045 \\
\hline Ash-throated flycatcher hatch success & 138 & Noise*+ & Year & 3 & 0.024 & 75.027 & 75.280 & 0.126 \\
\hline Mountain bluebird hatch success & 93 & Intercept & None & 1 & 0 & 56.586 & & $\mathrm{Na}$ \\
\hline Nestling feather growth (PC1) & 272 & $\begin{array}{c}\text { Noise }_{\text {quad }} \\
\text { Species* }\end{array}$ & $\begin{array}{c}\text { Year } \\
\text { Nest box } \\
\text { Nest ID }\end{array}$ & 9 & 0.907 & 295.644 & 353.080 & $<0.001$ \\
\hline Nestling body size (PC2) & 272 & $\begin{array}{c}\text { Noise }_{\text {quad }}{ }^{*} \\
\text { Species* } \\
\text { Chicks*_- }^{*} \\
\text { Distance*_- } \\
\text { Lay date*_- }\end{array}$ & Nest ID & 10 & 0.739 & 309.872 & 364.547 & $<0.001$ \\
\hline
\end{tabular}

All models presented are best-performing models. The term for life stage is included as the effect of the provisioning stage on the dependent variable. The term "distance" refers to the distance in meters from the nest box to the well pad center or compressor station. Models that do not include random effects were run as GLMMs following our described methods. k, parameters estimated; $\mathrm{Na}$, not applicable.

*Predictors that do not include zero in their $85 \%$ confidence limits; all continuous predictors are marked with the direction of their effect on the dependent variable.

hearing birdsong could be used as a safety signal in birds, and continual masking could chronically impair risk perception, leading to environmental uncertainty and activation of the stress response. While birds are away from the nest on foraging trips, noise throughout the territory (53) could decrease hunting efficiency ( 7 , 50 ), reducing energy intake and leading to increased allostatic load relative to individuals in quieter territories. Unlike adults, nestlings are incapable of escaping nest boxes and are constantly exposed to noise. This chronic, inescapable disturbance could stimulate stress and hypocorticism in nestlings through reduced reception of heterospecific (48) or parental (64) cues. Alternatively, the effect of compressor noise on parental vocal behavior (65) could interact with the effects of masking and lead to reduced detectability and increased uncertainty about environmental risk. Provisioning behavior could also be negatively affected by noise, leading to increased allostatic load in nestlings, discussed more below.

We also tested if, as in other systems, responses to acute stressors in animals under chronic stress were higher when exposed to heterotypic stressors. We measured cort levels in nestlings $10 \mathrm{~min}$ after capture and fit models similar to those for baseline measurements. The model with a common effect for noise but with species-specific differences best explained acute stressor-induced cort levels in nestlings. In contrast to baseline cort results, the effect of noise on acute stressor-induced cort was positive (LMM, Gaussian distribution, $\beta_{\text {noise }}=1.297,85 \% \mathrm{CI}$ : 0.067-2.538) (Fig. 2 and Table 1). The finding of suppressed baseline cort and increased acute stress-induced cort is consistent with many laboratory studies on model species, which suggest that hypocorticism results from chronic psychological stress (reviewed in ref. 26). Sensitization of cort response to acute stressors following exposure to a chronic stressor has also been found in nestling European starlings exposed to a chronic psychological stress protocol (32) but not in wild-caught adult birds exposed to a similar treatment in a laboratory setting (33). This response could be adaptive in nestlings experiencing increased perceived predation risk, as a heightened reactivity during this stage could prime them for more efficient escape effort (66). However, early fledging might trade off with the accumulation of body mass, which can reduce the probability of postfledgling survival (67-69). Although hypocorticism has been proposed as a protective response to increased allostatic load that might allow affected individuals to avoid the most serious effects of overload states (39), the attenuation of baseline cort is also potentially harmful and has been associated with inflammation, disease susceptibility (25), anxiety (43), and reduced exploration of novel objects (70). Thus, studies that explore hormone signaling and survivorship of individuals are necessary to fully quantify the costs of these responses to noise.

Effect of Noise on Fitness: Hatching Success. We found that a summary model including all species yielded uninformative results, and we therefore present species-specific models for hatching success (Table 1). Results from these models suggest that hatching success was significantly affected by noise in one species, the noise-tolerant western bluebird (53). In support of our prediction that increased noise would lead to decreased fitness, hatching success in the western bluebird was negatively associated with noise levels at the nest box [generalized linear mixed-effect model (GLMM), binomial distribution, $\beta_{\text {noise }}=-0.483$, 85\% CI: -0.892 to -0.075 ] (Fig. 3 and Table 1). Egg-hatching rates in ash-throated flycatchers showed a weak, positive relationship with noise (GLMM, binomial distribution, $\beta_{\text {noise }}=0.658,85 \%$ CI: 0.036-1.376) (Table 1 ), but this model was indistinguishable from the null hypothesis [change in corrected Akaike information criterion $\left(\Delta \mathrm{AIC}_{\mathrm{c}}\right)=0.25$ ]. Similarly, there was no clear effect of noise on hatching rates in mountain bluebirds. Overall, results from all three species may be best explained by previously described nesting patterns. 


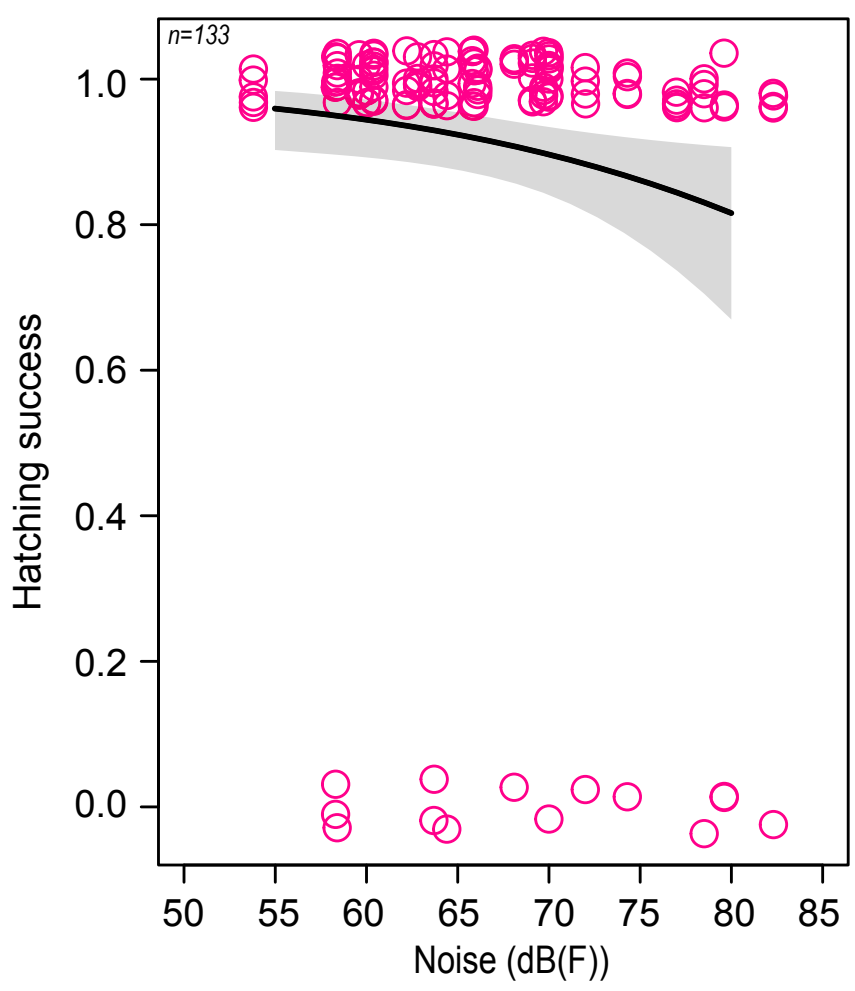

Fig. 3. Hatching success in the western bluebird was negatively affected by noise. The gray-shaded area indicates the $85 \% \mathrm{Cl}$.

The negative relationship between anthropogenic noise and hatching success in western bluebirds represents the strongest effect of noise on a direct measure of reproductive success in this study and is somewhat surprising, given previous results from this system that showed an even distribution of western bluebird nests across the noise gradient (53). The most parsimonious explanation is that the western bluebird may be caught in an equal-preference ecological trap driven by anthropogenic noise. An equal-preference trap occurs when a species shows equal preference for low- and high-quality habitats but incurs a reproductive cost in low-quality habitats (71). Both the ash-throated flycatcher and the mountain bluebird have been shown to avoid noise (53) and appear to escape the negative effects on hatching success related to high-amplitude noise exposure. That these population-level consequences were not indicated by occupancy data illustrates the importance of studies that combine occupancy, physiology, and fitness data.

One possible mechanism leading to reductions in hatch success is increased distraction and vigilance behavior in areas exposed to higher levels of noise, an effect well documented in the literature among birds, mammals, and arthropods (7, 50, 72-74). During the incubation period, increased vigilance by females could contribute to reduced hatching by a trade-off with incubation time leading to fluctuations of nest temperature and reduced time at optimum temperature $(75,76)$. Increased perceived predation risk has been shown to elevate vigilance via increased nest attentiveness among several bird species; however, this appears to come at the cost of reduced hatching success (52). Other possibilities include noise leading to a breakdown in courtship and copulation, or males, in contrast to females, might sort themselves by quality with noise, potentially leading to low-virility males in loud areas. Studies that investigate incubation rates and rhythms, courtship, nest attentiveness, and male quality in the context of noise are still needed to more conclusively determine causes of reduced egg hatching in loud areas. Nevertheless, regardless of the mechanisms involved, our results suggest that noise decreases a direct measure of fitness, hatching success, in the western bluebird, a species previously thought to be noise tolerant.

Effect of Noise on Fitness: Feather Development and Body Size. The effect of noise on fitness may manifest not only in hatching failures but also in reduced body condition of hatched chicks. Development and growth during the nestling stage is an important predictor of juvenile survival and thus acts as a useful surrogate to infer fitness potential in individuals exposed to noise $(77,78)$. We evaluated the effect of noise on nestling feather growth [principal component feather $\left(\mathrm{PC}_{\text {feather }}\right)$ ] and nestling body size [principal component size $\left(\mathrm{PC}_{\text {size }}\right)$ ] (see Table $\mathrm{S} 2$ for loadings) in a model including all species. Noise exposure was easily the strongest predictor of feather growth, showing a strong quadratic relationship with $\mathrm{PC}_{\text {feather }}$ (LMM, Gaussian distribution, $85 \%$ CI: -5.410 to -2.184 ) (Fig. 4 and Table 1). Noise had a positive impact on feather growth until $\sim 70 \mathrm{~dB}(\mathrm{~F})$, after which feather development was strongly reduced. Similarly, body size showed a quadratic relationship with noise, with decreases above $\sim 70 \mathrm{~dB}(\mathrm{~F})$ (LMM, Gaussian distribution, 85\% CI: -2.589 to -0.499 ) (Fig. 4 and Table 1). These results also support the hypothesis that noise decreases fitness. However, the nonlinear effect of noise on both feather growth and body size was not predicted. This demonstrates that, either directly or indirectly, acoustic disturbance gradients can elicit complex responses.

High levels of noise exposure could distract parents and lead to increased vigilance and reduced provisioning efforts that result in body size reductions (7), a situation that might also partly explain the development of hypocorticism in nestlings. Additionally, the ability of the birds in our study, which are all insectivorous, to find prey could also be diminished at sites with elevated levels of noise $(50,79)$. Several consequences are linked to smaller nestlings, such as failure to return from migration (80), occupancy of low-quality breeding habitat (81), and reduced reproductive success (82). Reduced feather development also likely decreases the ability to escape predators during fledgling stage (83).

At intermediate amplitudes nestlings exhibited accelerated growth of both feathers and body size. These moderate levels may increase pressure to develop faster and fledge earlier, while not incurring the costs of reduced provisioning in high-noise exposure. As well, previous results in this system show that avian nest predators are sensitive to and avoid loud areas (2). It could be that, at intermediate amplitudes, breeding birds experience a noise-mediated predator shield (84), in which predators are excluded but the consequences of noise on communication, cue detection, and distraction are minor or not perceived by individuals. This scenario would further facilitate provisioning and should be tested with experimental introductions of multimodal predator stimuli placed within medium-amplitude zones. If the absence of predators in areas where noise has not yet degraded perception creates conditions in which parental care is enabled, we would expect to see negative effects of the proposed predator treatment on nestling development.

At lower amplitudes, nestlings had feather growth and body size more comparable to those in individuals from the loudest locations, perhaps reflecting perceived (and real) presence of predators or increased detectability of con- and heterospecific acoustic signals about predators. It is worth noting that adult females and nestlings experience higher baseline cort in quiet areas, although it is unlikely that habitats with more natural acoustic conditions are poorer-quality environments for breeding. Thus, given these documented physiological changes (e.g., hypocorticism and body condition), further experiments addressing longer-term impacts of noise on survivorship of fledglings are needed.

We argue that the nonlinear effects of noise on development are best explained using the same mechanism that may cause chronic stress and hypocorticism: masking of acoustic cues that impairs risk perception and can lead to decreased provisioning effort. In other words, noise exposure creates sensory conditions 

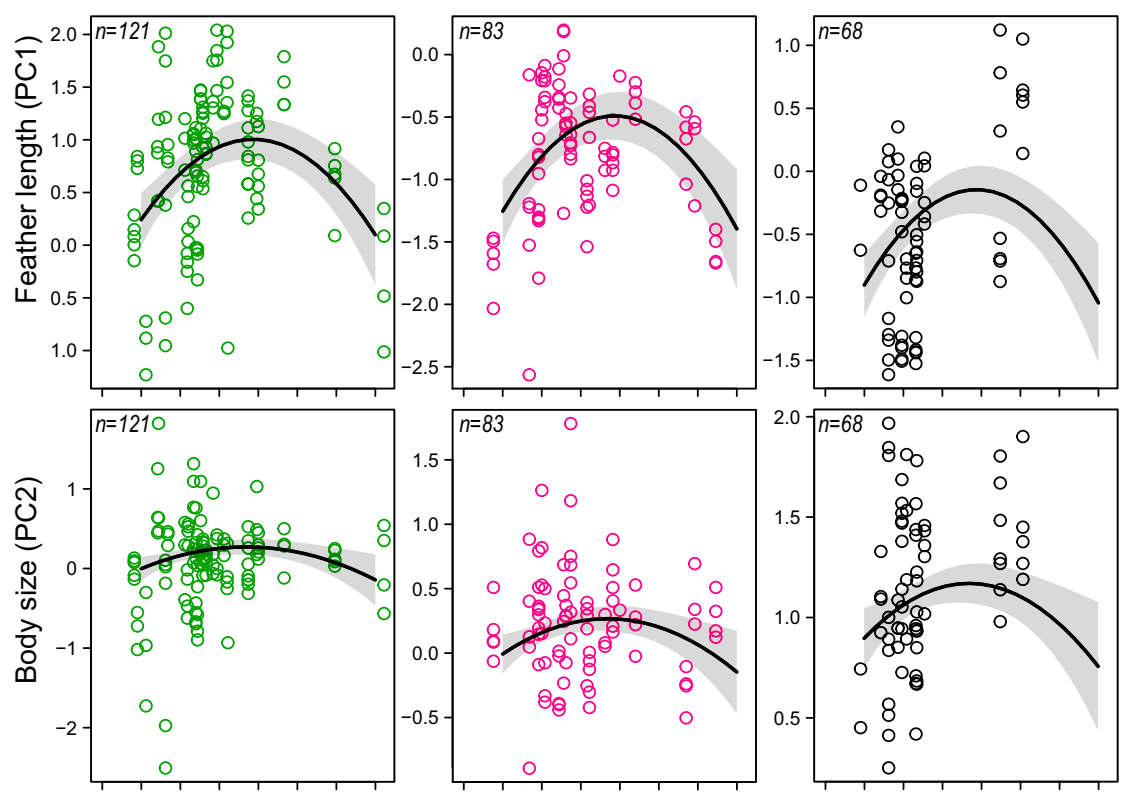

$\begin{array}{llllllll}50 & 55 & 60 & 65 & 70 & 75 & 80 & 85\end{array}$

$\begin{array}{llllllll}50 & 55 & 60 & 65 & 70 & 75 & 80 & 85\end{array}$ Noise $(\mathrm{dB}(\mathrm{F}))$

$\begin{array}{llllllll}50 & 55 & 60 & 65 & 70 & 75 & 80 & 85\end{array}$

Species legend

Ash-throated flycatcher

Western bluebird

Mountain bluebird

Fig. 4. The relationship between noise exposure and nestling development, represented by principal components axes, in all three species. Noise exposure had a nonlinear effect on feather development (Upper Row) and body size (Lower Row) in nestlings that was supported across species. The gray-shaded areas indicate the $85 \%$ confidence intervals for each estimated effect.

analogous to actual high predation risk, leading to increased vigilance or distraction but with no mechanism for escape.

Effect of Cort on Fitness. Surprisingly, there was no relationship between nestling baseline or acute stressor-induced cort on either nestling body condition PC axis. Instead, maternal baseline cort levels had strong influences on body condition, but with stage- and species-specific variation. For example, during provisioning, the relationship between adult female baseline cort and nestling body condition is species specific. Maternal baseline cort had a negative effect on nestling $\mathrm{PC}_{\text {feather }}$ in ash-throated flycatchers (LMM, Gaussian distribution, $\beta_{\text {cort }}=-0.257,85 \%$ CI: -0.363 to -0.150 ) (Table 2) and a positive effect in western bluebirds (LMM, Gaussian distribution, $\beta_{\text {cort }}=0.900$, 85\% CI: $0.673-$ 1.124; Table 2). Adult female baseline cort levels were negatively associated with nestling $\mathrm{PC}_{\text {size }}$ in provisioning western bluebirds (LMM, Gaussian distribution, $\beta_{\text {cort }}=-0.183,85 \%$ CI: -0.343 to -0.025 ) (Table 2 ) and were positively associated in mountain bluebirds (LMM, Gaussian distribution, $\beta_{\text {cort }}=$ 0.383, 85\% CI: $0.162-0.608$ ) (Table 2). These results suggest that direct relationships between cort and fitness depend on the context of life history and species.

In contrast to provisioning, during incubation, maternal baseline cort had a positive effect on hatching success (GLMM, binomial distribution, $\beta_{\text {cort }}=0.323,85 \%$ CI: $0.059-0.668$ ) (Fig. 5 and Table 2) that was supported across species. The finding that lower baseline cort during incubation is linked to reduced hatching success is similar to results found in free-living house sparrows (Passer domesticus) (85) and tree swallows (Tachycineta bicolor) (86) and offers further support for the idea that down-regulation of cort can have negative reproductive effects. This suggests that lower baseline cort levels may be useful in a conservation context as an indicator of low-quality habitat. See Tables S8-S11 for a more detailed account of the effect of cort on fitness.

\section{Conclusion}

We leveraged a natural experiment in a wildlands system positioned in a large-scale spatial gradient of anthropogenic noise to uncover a consistent trend of hypocorticism and complex and, in some cases, nonlinear fitness responses to noise exposure in a community of birds. Our work provides a predictive framework for understanding how chronic noise affects wildlife that is consistent with our landscape-scale and multispecies results as well as findings from several laboratory experimental systems in vertebrates $(25,32)$.

Chronic noise exposure masks critical acoustic cues $(8,26,47$, 50) and can increase environmental uncertainty that alters risk perception, potentially driving reductions to provisioning rates through a trade-off between vigilance and parental care. If nestlings employ compensatory strategies to cope with demands of reduced investment, earlier fledging at smaller body size should lead to net reductions in survival and success as juveniles and adults (67-69). Surprisingly, however, we also find that medium amplitudes of noise are associated with potentially positive fitness outcomes among offspring, suggesting that the consequences of altered environmental risk perception via the introduction of sensory pollutants can be complex.

The critical discovery is that there is a strong and consistent multispecies pattern of hypocorticism in response to increased noise amplitude that is linked to negative fitness consequences. This suggests an updated framework for how noise affects wildlife and strengthens the case for reassessment of conservation physiology theoretical models. Although there is an historical bias to expect elevated basal GCs in response to exposure to chronic 
Table 2. Effects of cort on fitness

\begin{tabular}{|c|c|c|c|c|c|c|c|c|}
\hline Dependent variable & $N$ & Fixed effects & Random effects & k & $\mathrm{R}^{2}$ & $\mathrm{AlC}_{\mathrm{c}}$ & Null $\mathrm{AIC}_{\mathrm{c}}$ & $\chi^{2}$ \\
\hline \multicolumn{9}{|c|}{ Fitness predicted by maternal baseline cort } \\
\hline Hatching success & 120 & $\begin{array}{l}\text { Baseline cort* } \\
\text { Species* }\end{array}$ & None & 4 & 0.190 & 90.649 & 92.459 & 0.044 \\
\hline Nestling body size (PC2) & 96 & $\begin{array}{l}\text { Baseline cort+ } \\
\text { Species* } \\
\text { Cort: species* }^{*} \\
\text { Distance }{ }^{*}- \\
\text { Lay date*_- }\end{array}$ & Site & 10 & 0.802 & 99.297 & 184.633 & $<0.001$ \\
\hline \multicolumn{9}{|c|}{ Fitness predicted by nestling baseline cort } \\
\hline \multicolumn{9}{|c|}{ Fitness predicted by nestling acute-stressor induced cort } \\
\hline Nestling feather growth (PC1) & 161 & $\begin{array}{l}\text { Acute cort+ } \\
\text { Species* }\end{array}$ & Nest ID & 6 & 0.885 & 182.780 & 217.760 & $<0.001$ \\
\hline Nestling body size (PC2) & 161 & $\begin{array}{l}\text { Acute cort+ } \\
\text { Species* }\end{array}$ & Nest ID & 6 & 0.705 & 183.643 & 212.253 & $<0.001$ \\
\hline
\end{tabular}

Models are top models or are the highest performing models within two $\mathrm{AIC}_{\mathrm{c}}$ that included a variable for cort. This table follows the formatting described in the legend of Table 1. Acute cort, acute stressor-induced cort; $k$, parameters estimated.

*Predictors that do not include zero in their $85 \%$ confidence limits; all continuous predictors are marked with the direction of their effect on the dependent variable.

stressors, a careful analysis of field and laboratory studies of diverse nonmammalian and mammalian species revealed that there is no consensus endocrine response to chronic stress (87). Our work raises a subtle but important point. There may be consistent responses, such as hypocorticism, within the context of chronic, inescapable noise exposure for avian breeding communities. However, the body of evidence suggests GC regulation is also context dependent, and rather than expecting simple generalities about GC response to hold broadly, it is more critical to document dysregulation, along with associated negative health consequences $(88,89)$. The next frontier in conservation physiology research may be understanding the physiological and behavioral consequences of chronic adverse experience and GC dysregulation in the context of the collective adaptive or maladaptive behavioral, immune (e.g., inflammatory), autonomic, and neuroendocrine mediator responses (i.e., those involved in growth, reproduction, and metabolism) $(90,91)$.

We conclude by noting that conditions at our sites are not unusually loud compared with anthropogenic noise found in many areas across the United States, or globally. In the contiguous United States, estimates of the land area exposed to even moderate amplitude increases of $10 \mathrm{~A}$-weighted decibels [ $\mathrm{dB}(\mathrm{A})]$ above natural levels is $\sim 485,268.16 \mathrm{~km}^{2}$ (92), and highly restricted protected areas and critical habitat for species of concern are not immune (3). A $10 \mathrm{~dB}(\mathrm{~A})$ increase above natural levels translates into a $90 \%$ decrease in listening area $(1,3)$ (i.e., the spatial extent of detection of acoustic signals or cues)clearly a drastically reduced perceptual world. In this era of unprecedented, large-scale human-driven environmental change, preservation or recovery of natural acoustic conditions should be a key aspect of conservation planning and is a critical step toward successful conservation of protected species.

\section{Materials and Methods}

Study System. We conducted fieldwork, following University of Colorado Boulder Institutional Animal Care and Use Committee guidelines (Protocol 1404.03), at a long-term study site in the Bureau of Land Management's Rattlesnake Canyon Habitat Management Area (RCHMA) in NW New Mexico during late spring and early summers from 2011 to 2014. The piñon (Pinus edulis)-juniper (Juniperus osteosperma) woodland and shrub grassland ecosystem of RCHMA is heavily affected by large-scale development of oil and gas infrastructure. Although developed by industry, RCHMA is remote, and animals in this region have very little contact with humans outside of minimally trafficked dirt roads and exposure to industry workers on well pads. Throughout this system, we installed a network of 240 cedar latched-roof nest boxes (53). Although nest boxes were designed to exclude common opportunistic nest predators such as Woodhouse's scrub-jay (Aphelocoma woodhouseii) and the least chipmunk (Tamias minimus) that appear largely responsible for nest predation in this system $(2,6)$, instances of predation by generalists such as deer mice (Peromyscus spp.) and bull snakes (Pituophis catenifer sayi) were occasionally observed at nest boxes across all noise levels.

We utilized the gradient of noise at RCHMA by placing nest boxes throughout the study area in 12 pairs of control and treatment sites, with 10 boxes per site. All sites were fully operational with nearly identical industrial equipment and similar levels of human activity on treatment and control sites (SI Materials and Methods). The key distinction between treatment and control sites was the presence of large compressor engines, which constantly produced high-amplitude, low-frequency noise on treatment sites (Fig. 1). Each control site was located at least 500 but no more than $1,000 \mathrm{~m}$ from its treatment pair, assuring that it was close enough to the treatment site to control for localized factors related to land cover composition but was far enough away to not be significantly affected by the noise from the compressor. Each control site was at least $500 \mathrm{~m}$ from any other noise-producing wells that were not involved in this study. Noise levels across all pairs of treatment and control sites differed significantly, while forest cover and vegetation did not $(2,53)$. We placed nest boxes in a circular pattern at $\sim 75 \mathrm{~m}, 125 \mathrm{~m}$, and $175 \mathrm{~m}$ from the center of the well pad on control sites and from the compressor on treatment sites (Fig. 1). By placing the boxes at uniform distances from site centers we control for the effect of disturbance created by industry workers servicing equipment. 


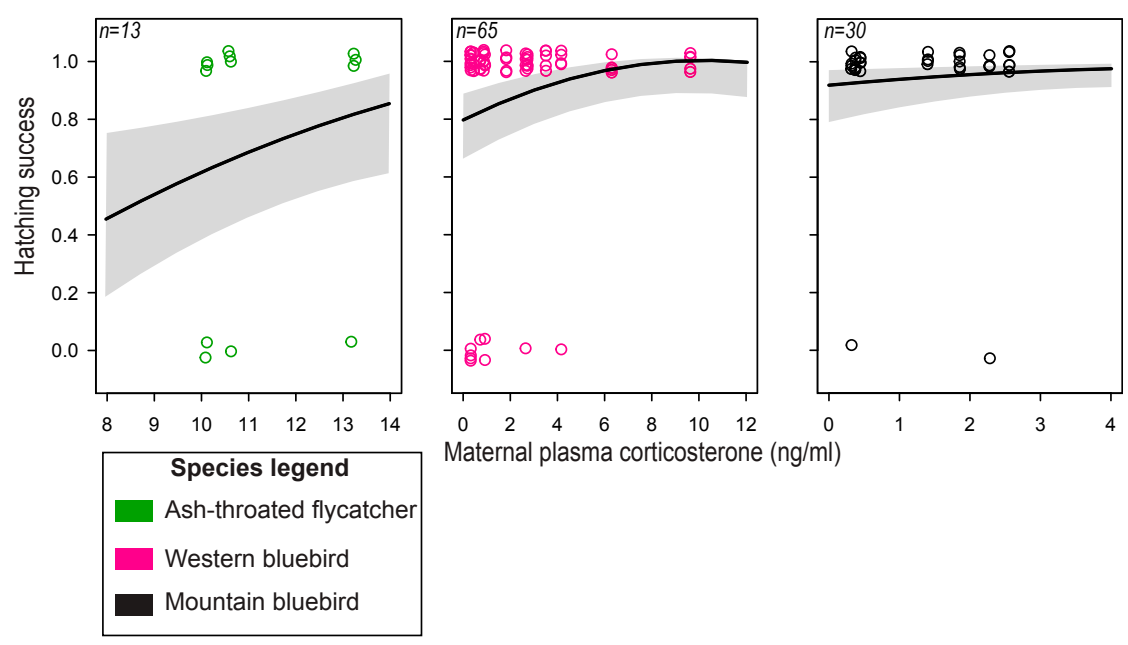

Fig. 5. Adult female baseline cort, measured during incubation, was positively associated with hatching success. The gray-shaded areas indicate the $85 \%$ confidence intervals for each estimated effect.
Nest Monitoring. We began monitoring nest boxes in early May each year, coinciding with the start of breeding season. Following a system-wide check for nesting activity, each box was monitored biweekly. Upon recording nesting activity in a box, we rated each nest as $25,50,75$, or $100 \%$ complete to prioritize further monitoring efforts. We checked complete nests every other day until at least one egg had been laid. However, logistical constraints sometimes restricted searching efforts. When more than one egg was found in a nest, we followed standard methodology $(93,94)$ and used natural history information on egg-laying intervals and incubation periods $(57,95,96)$ to back-calculate the initial lay date. Observations continued until the date when the first chick of each brood hatched, or "day zero." These data were used to schedule the nestling sampling date, which allowed the chicks to develop without unnecessary disturbance by our research team until day 12 .

Capture Methods and Hormone Assays. Nestlings were in prefledging stage during sampling and were hand-captured from the box. We were not able to differentiate between nestling sexes. Adults were hand-captured with the use of a sliding-door trap on the nest box initiated by a researcher hidden behind a bush and holding a line attached to the hole-block. We focused our adult study on breeding females only, and we identified females through behavior and coloration and, after capture, using the presence or absence of a brood patch. Thus, we were able to take into full account the effects of parental sex and life stage, which, when not controlled, can obscure important signals due to innate differences in GC levels between these groups (97). Once the target adult female entered the box, the line was pulled, and the timer was started.

Blood was taken within $3 \mathrm{~min}$ after capture from each individual to measure baseline levels of stress hormone (98). Less than $100 \mu \mathrm{L}$ of blood per individual was collected into heparinized hematocrit tubes from a puncture by a sterile needle in the brachial vein and was stored on ice until centrifugation. Birds were banded with standard issue metal bands from the US Geological Survey Bird Banding Laboratory (\#22837). We also measured body mass, wing length, tail length, and tarsus length for a general gauge of overall condition after baseline samples had been collected. After $10 \mathrm{~min}$ of restraint in a cloth sack, we sampled individuals for acute stressor-induced cort levels. We recognize that our protocol is shorter than typical stressseries restraint protocols, and we present these data as indicators of HPA responsiveness and not the maximum amount of cort released in response to a stressor. However, $10 \mathrm{~min}$ of restraint is likely enough time to elicit maximum cort release in birds (99-101). Due to concerns about nest abandonment, which reduced sampling feasibility in these species, we do not include acute stressor-induced cort measurements from adults. Details on sample handling, accuracy, and variation, especially with regard to low concentrations of cort, are available in SI Materials and Methods.

Measurement of Noise and Other Habitat Factors. We measured the equivalent continuous sound level [ $\mathrm{L}_{e q}, \mathrm{~dB}(\mathrm{~F})$, fast response, re. $20 \mu \mathrm{Pa}$ ] for 1 min at every nest box using a Larson-Davis System 824 sound pressure meter. See Kleist et al. (53) and Fig. S1 and SI Materials and Methods for more details on sound measurements. Tree cover was measured using ArcGIS and National Land Cover Dataset following methods described by Kleist et al. (53). We include tree cover because all three focal species prefer open, sparse shrublands rather than closed, forested habitats $(57,95,96)$. Additionally, we include the dis- tance to the center of the well pad to control for the effect of nest box's proximity to the well pad, which, irrespective of noise, may include low levels of chemical pollution and the infrequent presence of humans.

Temporal and Life History Factors. Baseline and acute stressor-induced levels of cort can relate to seasonality, life stages, and brood size, and we gathered data to control for these effects (21). We included sampling time as a fixed effect because GC levels are known to fluctuate throughout the day (25, 102). We included lay date in models since this variable corresponds with peaks in food availability and likely affects cort, relative to individual arrival times. Recent work suggests that cort levels are context dependent $(27,66$, 103) and that, within the breeding attempt, brooding and provisioning might require different amounts of cort; i.e., increased cort can facilitate provisioning (104). To control for these differences, we differentiate between blood drawn from brooding or provisioning adult females. Additionally, nest investment and reproductive potential can influence cort levels (103), and although we are not able to test directly for an effect of maternal age on nestling response, we do include a nest ID variable to control for individual effects. Finally, the brood size in each nest was recorded to control for the increased challenge of rearing large broods, which has been shown to affect incubation and lead to decreases in nest success (105).

Accounting for Potential Self-Sorting. In the event that lower-quality birds are relegated to or inadvertently select habitats with more noise exposure, the results of an analysis seeking to determine the effect of noise per se would potentially be biased. We tested whether this was a possibility by measuring body mass of all adult females, which is a reliable indicator of condition (106), before performing further analyses. We created linear models with noise and female body weight to determine if any correlation existed between noise levels at the nest box $[\mathrm{dB}(\mathrm{F})]$ and female condition. Across RCHMA, we found no evidence that heavier, higher-quality adult females were preferentially selecting quieter locations for nesting (Table S1), and therefore any variation in fitness and stress hormones is likely a result of habitat factors present at the nest site.

Model Testing Framework. We used LMM and GLMM models with the Ime4 package in the R statistical language, including a fixed term for "species," to test for effects of noise on cort and several measures of fitness, including hatching success and nestling body condition. We also tested for any relationship between cort and fitness (27). When species was significant as a fixed effect, we examined species-specific models.

The first model set examined the effects of noise on both nestling and adult female cort levels and included continuous fixed effects for noise, species, tree cover, distance to well pad, lay date, time of day, brood size and, in adults, a categorical effect for life stage, included as either incubation or provisioning. We tested baseline cort in adults and both baseline and acute stressor-induced cort, measured $10 \mathrm{~min}$ after capture, in nestlings.

The second model, which is the first of two models focused on uncovering the effect of noise on fitness, explored the relationship between noise and egg-hatching success. We defined hatching success as a binomial response in which each egg that was laid in a nest was included; those that hatched were marked as a 1, and those that did not hatch were marked as 0 (107). The 
binomial response term for hatching was included in models with noise, species, lay date, distance to well pad, tree cover, and clutch size.

In addition to measuring the effect of noise and other factors on hatching success, a direct measure of reproductive success, we created a third modeling set that included nestling condition as a response term. Nestling developmental changes can be a subtler but equally important indicator of fitness (52, 77). We used principal components analysis (PCA) with varimax rotation (principal function in the psych library for $\mathrm{R}$ ) to load measurements of nestling wing chord (in millimeters), rectrices (in millimeters), tarsus length (in millimeters), and mass (in grams) onto appropriate axes. These measurements were all taken on the 12th day after hatching, because that is the final day where nest visitation is unlikely to instigate disturbance-induced prefledging (North American Bluebird Society, www.nabluebirdsociety.org). These morphological measures loaded on two axes with PC1 explaining $47 \%$ and PC2 37\% of the variation in the data (Table S2). Wing chord length and length of rectrices loaded strongly onto $\mathrm{PC1}$, while mass and tarsus length loaded strongly onto PC2; because of these loadings, we named these axes " $\mathrm{PC}_{\text {feather" }}$ " and " $\mathrm{PC}_{\text {size, }}$ " respectively. We placed these axes as response terms in models that include fixed effects for noise, species, tree cover, distance to well pad, lay date, and brood size. Because nestling mass is known to fluctuate throughout the day, we also included a term for time of day in model selection for $\mathrm{PC}_{\text {size. }}$ After initial exploration of data distributions, we included both $P C_{\text {feather }}$ and $\mathrm{PC}_{\text {size }}$ as second-order polynomials, suggesting that developmental effects of noise might vary nonlinearly with amplitude. In experimental research with humans, vigilance is known to peak at medium amplitudes of noise (108). This has important implications, via noise-mediated foragingvigilance trade-offs (7), and could translate to reduced provisioning rates and altered development in nestlings, in a similar nonlinear fashion.

Finally, we explored the relationship between cort and fitness. In three separate models, we incorporated nestling body condition as a response to nestling baseline cort, nestling acute stressor-induced cort, and maternal baseline cort measured during provisioning. We also analyzed the effect of maternal baseline cort measured during incubation on hatching success. For all cort-fitness models we included an interaction between cort and species, as cort levels are known to vary systematically across species. Although the focus of this paper is to explore the effect of acoustic habitat disturbance on

1. Barber JR, Crooks KR, Fristrup KM (2010) The costs of chronic noise exposure for terrestrial organisms. Trends Ecol Evol 25:180-189.

2. Francis $C D$, Ortega $C P$, Cruz $A$ (2009) Noise pollution changes avian communities and species interactions. Curr Biol 19:1415-1419.

3. Buxton RT, et al. (2017) Noise pollution is pervasive in U.S. protected areas. Science 356:531-533.

4. Shannon G, et al. (2015) A synthesis of two decades of research documenting the effects of noise on wildlife. Biol Rev Camb Philos Soc 91:982-1005.

5. Crino OL, Van Oorschot BK, Johnson EE, Malisch JL, Breuner CW (2011) Proximity to a high traffic road: Glucocorticoid and life history consequences for nestling whitecrowned sparrows. Gen Comp Endocrinol 173:323-332.

6. Francis CD, Kleist NJ, Ortega CP, Cruz A (2012) Noise pollution alters ecological services: Enhanced pollination and disrupted seed dispersal. Proc Biol Sci 279:2727-2735.

7. Ware HE, McClure CJW, Carlisle JD, Barber JR (2015) A phantom road experiment reveals traffic noise is an invisible source of habitat degradation. Proc Natl Acad Sci USA 112:12105-12109.

8. Kleist NJ, Guralnick RP, Cruz A, Francis CD (2016) Anthropogenic noise weakens territorial response to intruder's songs. Ecosphere 7:e01259.

9. Potvin DA, Curcio MT, Swaddle JP, MacDougall-Shackleton SA (2016) Experimental exposure to urban and pink noise affects brain development and song learning in zebra finches (Taenopygia guttata). PeerJ 4:e2287.

10. Habib L, Bayne EM, Boutin S (2006) Chronic industrial noise affects pairing success and age structure of ovenbirds Seiurus aurocapilla. J App/ Ecol 44:176-184.

11. Roca IT, et al. (2016) Shifting song frequencies in response to anthropogenic noise: A meta-analysis on birds and anurans. Behav Ecol 27:1269-1274.

12. Slabbekoorn H (2013) Songs of the city: Noise-dependent spectral plasticity in the acoustic phenotype of urban birds. Anim Behav 85:1089-1099.

13. Blickley JL, et al. (2012) Experimental chronic noise is related to elevated fecal corticosteroid metabolites in lekking male greater Sage-Grouse (Centrocercus urophasianus). PLoS One 7:e50462.

14. Powell DM, Carlstead K, Tarou LR, Brown JL, Monfort SL (2006) Effects of construction noise on behavior and cortisol levels in a pair of captive giant pandas (Ailuropoda melanoleuca). Zoo Biol 25:391-408.

15. Westlund K, et al. (2012) Physiological and behavioural stress responses in cynomolgus macaques (Macaca fascicularis) to noise associated with construction work Lab Anim 46:51-58.

16. Rolland RM, et al. (2012) Evidence that ship noise increases stress in right whales. Proc Biol Sci 279:2363-2368.

17. Crino OL, Johnson EE, Blickley JL, Patricelli GL, Breuner CW (2013) Effects of experimentally elevated traffic noise on nestling white-crowned sparrow stress physiology, immune function and life history. J Exp Biol 216:2055-2062. physiology and fitness, and not the effect of maternal cort on nestling growth, we included these models to more fully examine if changes to baseline cort resulting from noise exposure are linked to negative fitness consequences. We did not use noise as a predictor in these models to better isolate effects of maternal cort on fitness-relevant measures.

For all models, we included random effects terms to control for variation in data attributable to environmental factors associated with pair, site, and nest box (Fig. 1) and also included a random effect for year. Nestling cort and fitness models included a random effect for Nest ID to control for brood identity in nestlings and for multiple breeding attempts in adults.

Model selection was conducted using an information criterion approach to compare $\mathrm{AlC}_{\mathrm{c}}$ scores between models. All continuous fixed effects were transformed to z-scores using the scale function in $\mathrm{R}$, which allows direct comparison of effects and improves model fit. After initially fitting the full model, random effects that explained near-zero variance (variance $\leq 0.0001$ ) were removed to improve the fit of the model (109). Additionally, we refit models as GLMM if all random effects were removed during model selection. We considered models with all combinations of hypothesized predictor variables and designated all models within two $\triangle \mathrm{AIC}_{\mathrm{c}}$ and that differed from the null model with identical random effects as determined by a likelihood ratio test as strongly supported. We calculated effect sizes and $85 \%$ Cls for individual predictors from supported models $(7,110)$. For full results, including effects of other predictors and model selection, see Tables S3-S7. All data and the R code used to produce this work will be made available online in a Dryad digital data repository.

ACKNOWLEDGMENTS. We thank the many field and laboratory assistants who helped make this work possible, especially Clare O'Connor-Seville, Sara Bombaci, Ian Harold, Skye Salganek, Anna Vinton, and Kate Zator; Jesse Barber for constructive comments on earlier drafts; Joseph Ortega and Rebecca Safran for generous use of laboratory space and equipment during assay procedures; Jim Chace for help with bird-banding logistics; and the reviewers and the editor for their comments and feedback throughout the review process. This study was funded by a National Geographic Research and Exploration Grant, National Science Foundation Grants CNH 1414171 and DEB 1556192 (to C.D.F.), a North American Bluebird Society grant, and funding from the University of Colorado Graduate School and Department of Ecology and Evolutionary Biology (N.J.K.).

18. Tempel DJ, Gutierrez RJ (2003) Fecal corticosterone levels in California spotted owls exposed to low-intensity chainsaw sound. Wildl Soc Bull 31:698-702.

19. Tennessen JB, Parks SE, Langkilde T (2014) Traffic noise causes physiological stress and impairs breeding migration behaviour in frogs. Conserv Physiol 2:cou032.

20. Kaiser K, et al. (2015) Effects of anthropogenic noise on endocrine and reproductive function in White's tree frog, Litoria caerulea. Conserv Physiol 3:cou061.

21. Wingfield JC, Romero LM (2015) Tempests, Poxes, Predators, and People (Oxford Univ Press, New York), 10.1093/acprof:oso/9780195366693.001.0001.

22. Campeau S, Watson SJ (1997) Neuroendocrine and behavioral responses and brain pattern of c-fos induction associated with audiogenic stress. J Neuroendocrinol 9:577-588.

23. Henkin RI, Knigge KM (1963) Effect of sound on the hypothalamic-pituitary-adrenal axis. Am J Physiol 204:701-704.

24. Sapolsky RM (2005) The influence of social hierarchy on primate health. Science 308 648-652.

25. Langgartner D, Füchsl AM, Uschold-Schmidt N, Slattery DA, Reber SO (2015) Chronic subordinate colony housing paradigm: A mouse model to characterize the consequences of insufficient glucocorticoid signaling. Front Psychiatry 6:18.

26. Templeton CN, Zollinger SA, Brumm H (2016) Traffic noise drowns out great tit alarm calls. Curr Biol 26:R1173-R1174.

27. Bonier F, Martin PR, Moore IT, Wingfield JC (2009) Do baseline glucocorticoids predict fitness? Trends Ecol Evol 24:634-642.

28. McEwen BS (2011) Neurobiology of interpreting and responding to stressful events: Paradigmatic role of the hippocampus. Comprehensive Physiology (John Wiley \& Sons, Inc., Hoboken, NJ), 10.1002/cphy.cp070409.

29. Herman JP, Cullinan WE (1997) Neurocircuitry of stress: Central control of the hypothalamo-pituitary-adrenocortical axis. Trends Neurosci 20:78-84.

30. McEwen BS, Wingfield JC (2003) The concept of allostasis in biology and biomedicine. Horm Behav 43:2-15.

31. Romero LM (2004) Physiological stress in ecology: Lessons from biomedical research Trends Ecol Evol 19:249-255.

32. Cyr NE, Michael Romero $L$ (2007) Chronic stress in free-living European starlings reduces corticosterone concentrations and reproductive success. Gen Comp Endocrinol 151:82-89.

33. Cyr NE, Earle K, Tam C, Romero LM (2007) The effect of chronic psychological stress on corticosterone, plasma metabolites, and immune responsiveness in European starlings. Gen Comp Endocrinol 154:59-66.

34. Wasser SK, Bevis K, King G, Hanson E (1997) Noninvasive physiological measures of disturbance in the Northern spotted owl. Conserv Biol 11:1019-1022.

35. Creel S, et al. (2002) Snowmobile activity and glucocorticoid stress responses in wolves and elk. Conserv Biol 16:809-814.

36. Scheuerlein A, Van't Hof TJ, Gwinner E (2001) Predators as stressors? Physiological and reproductive consequences of predation risk in tropical stonechats (Saxicola torquata axillaris). Proc Biol Sci 268:1575-1582. 
37. Raison CL, Miller AH (2003) When not enough is too much: The role of insufficient glucocorticoid signaling in the pathophysiology of stress-related disorders. $\mathrm{Am} J$ Psychiatry 160:1554-1565.

38. Pace TWW, Heim CM (2011) A short review on the psychoneuroimmunology of posttraumatic stress disorder: From risk factors to medical comorbidities. Brain Behav Immun 25:6-13.

39. Fries E, Hesse J, Hellhammer J, Hellhammer DH (2005) A new view on hypocortisolism. Psychoneuroendocrinology 30:1010-1016.

40. Reber SO, et al. (2016) Immunization with a heat-killed preparation of the environmental bacterium Mycobacterium vaccae promotes stress resilience in mice. Proc Natl Acad Sci USA 113:E3130-E3139.

41. Singewald GM, Nguyen NK, Neumann ID, Singewald N, Reber SO (2009) Effect of chronic psychosocial stress-induced by subordinate colony (CSC) housing on brain neuronal activity patterns in mice. Stress 12:58-69.

42. Cyr NE, Romero LM (2009) Identifying hormonal habituation in field studies of stress. Gen Comp Endocrinol 161:295-303.

43. Uschold-Schmidt N, Nyuyki KD, Füchsl AM, Neumann ID, Reber SO (2012) Chronic psychosocial stress results in sensitization of the HPA axis to acute heterotypic stressors despite a reduction of adrenal in vitro ACTH responsiveness. Psychoneuroendocrinology 37: 1676-1687.

44. Gil D, Gahr M (2002) The honesty of bird song: Multiple constraints for multiple traits. Trends Ecol Evol 17:133-141.

45. Phelps SM, Rand AS, Ryan MJ (2007) The mixed-species chorus as public information: Tungara frogs eavesdrop on a heterospecific. Behav Ecol 18:108-114.

46. Sullivan KA (1984) Information exploitation by downy woodpeckers in mixed-species flocks. Behaviour 91:294-311.

47. Grade AM, Sieving KE (2016) When the birds go unheard: Highway noise disrupts information transfer between bird species. Biol Lett 12:20160113.

48. Haff TM, Magrath RD (2013) Eavesdropping on the neighbours: Fledglings learn to respond to heterospecific alarm calls. Anim Behav 85:411-418.

49. Forsman JT, Mönkkönen $M$, Monkkonen M, Mönkkönen M, Monkkonen M (2001) Responses by breeding birds to heterospecific song and mobbing call playbacks under varying predation risk. Anim Behav 62:1067-1073.

50. Senzaki M, Yamaura Y, Francis CD, Nakamura F (2016) Traffic noise reduces foraging efficiency in wild owls. Sci Rep 6:30602.

51. Francis CDC, et al. (2017) Acoustic environments matter: Synergistic benefits to humans and ecological communities. J Environ Manage 203:245-254.

52. LaManna JA, Martin TE (2016) Costs of fear: Behavioural and life-history responses to risk and their demographic consequences vary across species. Ecol Lett 19:403-413.

53. Kleist NJ, Guralnick RP, Cruz A, Francis CD (2017) Sound settlement: Noise surpasses land cover in explaining breeding habitat selection of secondary cavity-nesting birds. Ecol App/ 27:260-273.

54. Duckworth RA, Badyaev AV (2007) Coupling of dispersal and aggression facilitates the rapid range expansion of a passerine bird. Proc Natl Acad Sci USA 104:15017-15022.

55. Kight CR, Saha MS, Swaddle JP (2012) Anthropogenic noise is associated with re ductions in the productivity of breeding Eastern Bluebirds (Sialia sialis). Ecol App/ 22 1989-1996.

56. Bhardwaj M, Dale CA, Ratcliffe LM (2015) Aggressive behavior by Western Bluebirds (Sialia mexicana) varies with anthropogenic disturbance to breeding habitat. Wilson J Ornithol 127:421-431.

57. Cardiff SW, Dittmann DL (2002) Ash-throated flycatcher. The Birds of North America, ed Poole A (Cornell Laboratory of Ornithology, Ithaca, NY). Available at https:// birdsna.org. Accessed May 25, 2017

58. Lohr B, Wright TF, Dooling RJ (2003) Detection and discrimination of natural calls in masking noise by birds: Estimating the active space of a signal. Anim Behav 65:763-777.

59. Alves D, Amorim MCP, Fonseca PJ (2016) Boat noise reduces acoustic active space in the lusitanian toadfish Halobatrachus didactylus. Proc Meet Acoust 27:10033.

60. Mason JT, McClure CJWW, Barber JR (2016) Anthropogenic noise impairs owl hunting behavior. Biol Conserv 199:29-32.

61. Parris KM, Schneider A (2009) Impacts of traffic noise and traffic volume on birds of roadside habitats. Ecol Soc 14:29.

62. MacLean SA, Bonter DN (2013) The sound of danger: Threat sensitivity to predator vocalizations, alarm calls, and novelty in gulls. PLoS One 8:e82384.

63. Moller AP, Møller AP (1992) Interspecific response to playback of bird song. Ethology 90:315-320.

64. Leonard ML, Horn AG (2012) Ambient noise increases missed detections in nestling birds. Biol Lett 8:530-532.

65. Francis CD, Kleist NJ, Davidson BJ, Ortega CP, Cruz A (2012) Behavioral responses by two songbirds to natural-gas-well compressor noise. Ornithol Monogr 74:36-46.

66. Jaatinen K, Seltmann MW, Öst M (2014) Context-dependent stress responses and their connections to fitness in a landscape of fear. J Zool (Lond) 294:147-153.

67. Perrins CM (1965) Population fluctuations and clutch-size in the great tit, Parus major. J Anim Ecol 34:601-647.

68. Lindén M, Gustafsson L, Pärt T (1992) Selection on feldging mass in the collared flycatcher and the great tit. Ecology 73:336-343.

69. Hõrak P, Tegelmann L, Ots I, Møller AP (1999) Immune function and survival of great tit nestlings in relation to growth conditions. Oecologia 121:316-322.

70. Slattery DA, et al. (2012) Behavioural consequences of two chronic psychosocial stress paradigms: Anxiety without depression. Psychoneuroendocrinology 37:702-714.

71. Robertson BA, Hutto RL (2006) A framework for understanding ecological traps and an evaluation of existing evidence. Ecology 87:1075-1085.

72. Chan AAY-H, et al. (2010) Increased amplitude and duration of acoustic stimuli enhance distraction. Anim Behav 80:1075-1079.

73. Chan AAY-H, Giraldo-Perez P, Smith S, Blumstein DT (2010) Anthropogenic noise affects risk assessment and attention: The distracted prey hypothesis. Biol Lett 6:458-461.
74. Francis CD, Barber JR (2013) A framework for understanding noise impacts on wildlife: An urgent conservation priority. Front Ecol Environ 11:305-313.

75. Wilson HR (1991) Physiological requirements of the developing embryo: Temperature and turning. Avian Incubation. Poultry Science Symposium (Butterworth, Kent, UK), Vol 22, pp 145-156.

76. Booth DT (1987) Effect of temperature on development of mallee fowl Leipoa ocellata eggs. Physiol Zool 60:437-445.

77. Magrath RDR (1991) Nestling weight and juvenile survival in the blackbird, Turdus merula. J Anim Ecol 60:335-351.

78. Naef-daenzer B, Nuber M (2013) Differential post-fledging survival of great and coal tits in relation to their condition and fledging date. J Anim Ecol 70:730-738.

79. Montgomerie R, Weatherhead PJ (1997) How robins find worms. Anim Behav 54: 143-151.

80. Merilä J, Svensson E (1997) Are fat reserves in migratory birds affected by condition in aarly life? J Avian Bio/ 28:279-286.

81. Verhulst S, Perrins CM, Riddington R (1997) Natal dispersal of great tits in a patchy environment. Ecology 78:864-872.

82. Haywood S, Perrins CM (1992) Is clutch size in birds affected by environmental conditions during growth? Proc $R$ Soc London SerB 249:195-197.

83. Cheng $Y-R$, Martin TE (2012) Nest predation risk and growth strategies of passerine species: Grow fast or develop traits to escape risk? Am Nat 180:285-295.

84. Shannon G, Cordes LS, Hardy AR, Angeloni LM, Crooks KR (2014) Behavioral responses associated with a human-mediated predator shelter. PLoS One 9:e94630.

85. Ouyang JQ, Sharp PJ, Dawson A, Quetting M, Hau M (2011) Hormone levels predict individual differences in reproductive success in a passerine bird. Proc Biol Sci 278: 2537-2545.

86. Bonier F, Moore IT, Martin PR, Robertson RJ (2009) The relationship between fitness and baseline glucocorticoids in a passerine bird. Gen Comp Endocrinol 163:208-213.

87. Dickens MJ, Romero LM (2013) A consensus endocrine profile for chronically stressed wild animals does not exist. Gen Comp Endocrinol 191:177-189.

88. Wikgren M, et al. (2012) Short telomeres in depression and the general population are associated with a hypocortisolemic state. Biol Psychiatry 71:294-300.

89. de Kloet ER (2003) Hormones, brain and stress. Endocr Regul 37:51-68.

90. McEwen BS (1998) Stress, adaptation, and disease. Allostasis and allostatic load. Ann $N$ Y Acad Sci 840:33-44.

91. Miller AH, Raison $\mathrm{CL}$ (2016) The role of inflammation in depression: From evolutionary imperative to modern treatment target. Nat Rev Immunol 16:22-34.

92. Mennitt D, Fristrup K, Nelson L, McKenna M (2013) Mapping the extent of noise on a national scale using geospatial models. J Acoust Soc Am 134:4159-4159.

93. Labarbera K, Llambías PE, Cramer ERA, Schaming TD, Lovette IJ (2010) Synchrony does not explain extrapair paternity rate variation in northern or southern house wrens. Behav Ecol 21:773-780.

94. Plummer KE, Bearhop S, Leech DI, Chamberlain DE, Blount JD (2013) Fat provisioning in winter impairs egg production during the following spring: A landscape-scale study of blue tits. J Anim Ecol 82:673-682.

95. Power HW, Lombardo MP (1996) Mountain bluebird. The Birds of North America, ed Poole A (Cornell Laboratory of Ornithology, Ithaca, NY). Available at https://birdsna. org. Accessed May 25, 2017.

96. Guinan JA, Gowaty PA, Eltzroth EK (2000) Western bluebird. The Birds of North America, ed Poole A (Cornell Laboratory of Ornithology, Ithaca, NY). Available at https://birdsna.org. Accessed May 25, 2017.

97. Busch DS, Hayward LS (2009) Stress in a conservation context: A discussion of glucocorticoid actions and how levels change with conservation-relevant variables. Biol Conserv 142:2844-2853.

98. Romero LM, Reed JM (2005) Collecting baseline corticosterone samples in the field: Is under 3 min good enough? Comp Biochem Physiol A Mol Integr Physiol 140:73-79.

99. Breuner CW, Patterson SH, Hahn TP (2008) In search of relationships between the acute adrenocortical response and fitness. Gen Comp Endocrinol 157:288-295.

100. Romero LM, Ramenofsky M, Wingfield JC (1997) Season and migration alters the corticosterone response to capture and handling in an Arctic migrant, the whitecrowned sparrow (Zonotrichia leucophrys gambelii). Comp Biochem Physiol C Pharmacol Toxicol Endocrinol 116:171-177.

101. Schoech SJ, Ketterson ED, Nolan V, Jr (1999) Exogenous testosterone and the adrenocortical response in dark-eyed juncos. Auk 116:64-72.

102. Love OP, Breuner CW, Vézina F, Williams TD (2004) Mediation of a corticosteroneinduced reproductive conflict. Horm Behav 46:59-65.

103. Dantzer B, Fletcher QE, Boonstra R, Sheriff MJ (2014) Measures of physiological stress: A transparent or opaque window into the status, management and conservation of species? Conserv Physiol 2:cou023.

104. Madliger CL, Semeniuk CAD, Harris CM, Love OP (2015) Assessing baseline stress physiology as an integrator of environmental quality in a wild avian population: Implications for use as a conservation biomarker. Biol Conserv 192:409-417.

105. Reid JM, Monaghan P, Ruxton GD (2000) The consequences of clutch size for incubation conditons and hatching success in starlings. Funct Ecol 14:560-565.

106. Labocha MK, Hayes JP (2012) Morphometric indices of body condition in birds: A review. J Ornithol 153:1-22.

107. Cooper CB, Hochachka WM, Butcher G, Dhondt AA (2005) Seasonal and latitudinal trends in clutch size: Thermal constraints during laying and incubation. Ecology 86:2018-2031.

108. Teichner WH, Arees E, Reilly R (1963) Noise and human performance, a psychophysiological approach. Ergonomics 6:83-97.

109. Bates DM, Kliegl R, Vasishth S, Baayen H (2015) Parsimonious mixed models. arXiv: 1506.04967

110. Arnold TW (2010) Uninformative parameters and model selection using Akaike's information criterion. J Wildl Manage 74:1175-1178. 